\title{
Social Media Networks as a Business Environment, During COVID-19 Crisis
}

\author{
Mihai C. ORZAN ${ }^{1}$ \\ Adina I. ZARA ${ }^{2}$ \\ Ştefan C. CĂESCU ${ }^{3}$ \\ Mihaela E. CONSTANTINESCU ${ }^{4}$ \\ Olguța A. ORZAN ${ }^{5}$
}

\begin{abstract}
Companies are now integrating social media marketing into their strategies and policies, for a better business performance. Social media campaigns are cost-effective and flexible in operations, offering many benefits. Between 15 - 30 August 2020 we created and managed a Facebook campaign for a local fashion brand. The online marketing becomes even more valuable in COVID-19 crisis, people shop and spend online more than ever. The marketing campaign generated important data to understand the customers demographic, interests, actions and helps us to make profiles of the potential clients. In this context we analyzed the conversion rate indicator, to understand if the marketing campaign was efficient or not. Conversion rate may not be the best to measure the success, but it is a great tool for tracking performance. We propose also the ROAS indicator, to measure the success of this marketing campaign
\end{abstract}

Keywords: social media, online marketing campaigns, analytics, business manager, conversion rate

JEL classification: M31, M37, O33, O35

DOI: $10.24818 / \mathrm{RMCI} .2021 .1 .64$

\section{Introduction}

Users accessing online social networks provide information about their interests, preferences, emotions and motivations. Their demographic profile, as well as the relationship between users are important aspects for the business environment. Companies can improve their services and products based on the users' appreciations

${ }^{1}$ Orzan C. Mihai, Faculty of Marketing, Academy of Economic Studies, E-mail: mihai.orzan@ase.ro, Telephone: +40722318332

2 Zara I. Adina, Faculty of Marketing, Academy of Economic Studies, E-mail: adinazara@gmail.com, Telephone: +40757069993

3 Căescu C. Ştefan, Faculty of Marketing, Academy of Economic Studies, E-mail: stefan.caescu@mk.ase.ro, Telephone: +40746013031

${ }^{4}$ Constantinescu E. Mihaela, Faculty of Marketing, Academy of Economic Studies, E-mail: mihaela.co@gmail.com, Telephone: +40721223896

5 Orzan A. Olguța, Department of Dermatology, University of Medicine and Pharmacy, "Carol Davila" Bucharest, E-mail: olguta@ gmail.com, Telephone: +40721250525

64 Review of International Comparative Management

Volume 22, Issue 1, March 2021 
and feedback. Social networks help companies to improve communication with potential clients. The communication process includes several phases: identification of information, information tracking, data preparation and analysis.

Social media marketing refers to the process of gaining website traffic and attention through social media networks (Barker, Barker, Bormann \& Zahay, 2016). Online social networks offer social, economic, political and educational benefits.

Social benefits:

- Extending the connections between people;

- Communities with different interests;

- Development of programs and activities within communities;

Economic advantages:

- Easy way to communicate with clients;

- Sales and marketing environment;

- Interaction between brands and clients, potential clients;

- Attracting new clients;

- Retention of existing clients;

- Environment for market research.

Political advantages:

- Direct communication between candidates and voters;

- Motivation of the electorate

- Action for certain causes

Educational advantages:

- Direct interaction between teachers and students;

- Real time collaboration;

- Remote collaboration between more teams in the same time;

- Easy way to disseminate information.

In the same time there are many challenges of social networks such as:

- Difficulties in protecting personal data;

- Spam;

- Addiction to online social networking;

- Issues in adapting to the real world and face to face communication and collaboration;

- Malware;

- Limitation to the online social communities.

The most used social network in Romania is Facebook, with over 10860 000 users, which represents a usage rate of $56.4 \%$ in January 2020, according to The Internet World Stats. 


\section{R O M A N I A}

RO - 19,237,691 population (2020) - Country Area: 238,391 sq km

Capital city: Bucharest - population 1,883,425 (2011 census)

GNI (per capita): \$12,301 (2018) per World Bank.

14,387,477 Internet users in Dec, 2018, 73.8\% penetration, per IWS.

$10,860,000$ Facebook subscribers in JAN/2020, 56.4\% penetration rate.

Local Time and Weather in Bucharest, Romania

Figure 1: Romania's internet and Facebook users

Social networks help companies to interact with their clients in many ways:

- Involves people in certain activities;

- Convert users into customers, activating the trust in their relationship;

- Build brand loyalty;

- Improve customer service and provide support when necessary;

- Encourage to build and develop new communities

Companies develop different applications that users can use in their online community. In the last 15 years social media networks have changed the way companies reach their target market. These changes influence how marketers operate marketing strategies and tactics (Alves, Fernandes \& Rapso, 2016).

Social media promotional campaigns are cost-effective and flexible in operations, offering many targeting possibilities and the ability to reach a large number of targeted audiences within less time (Iblasi, Bader \& Al-Qreini, 2016). Digital marketing enables businesses of all sizes to reach big online audiences in a cost effective and measurable manner (Miller, 2020) and to build brand awareness (Star, Marsico, Hernandes, 2020).

Facebook advertising campaigns could offer many benefits:

- companies can engage with people and strengthen their connection. Consumer engagement is a key factor to increase the effectiveness of marketing communication through social media (Sharma, Verma, 2018)

- convert potential clients into customers, achieving better confidence and trust in forming the customer relationship (Krishnan \& Rogers, 2014

- improve customer service;

- collect information about customers and their feedback

- build and increase brand loyalty;

- provide information about products and services to a specific target audience;

It is important to consider the future of social media in the context of marketing, since social media networks become a vital communication and marketing field for business. (Appel, Grewal, Hadi \& Stephen, 2019). Companies 
can benefit from social media marketing as a search engine marketing, content marketing, influencer marketing, direct-marketing or display advertising (Bala \& Verma, 2018).

\section{Facebook Marketing campaign - a case study of a fashion brand in Romania}

We created a Facebook Marketing Campaign for a Romanian fashion brand which is locally known for school backpacks and accessories. COVID-19 pandemic forced companies to adopt new strategies.

\section{a. General aspects about the marketing campaign "Back to School"}

The marketing campaign was active between 15 August to 30 August 2020 and its main objective was to generate sales for school backpacks. This fashion brand is a local brand producing trendy and modern backpacks for girls from primary and secondary school. The plan was to run this marketing campaign before school opening in September. For this marketing campaign a 360 degrees video was used, 7 second in length, with a product which was top selling for the last year. The campaign targeted teenagers. The advertisement text was simple and short focusing on the quality, originality and easy to wear models. The objective of the campaign was "Conversions". As a conversion event the 'Order placed' was used.

\section{b. Results of marketing campaign}

The marketing campaign was a successful one, with a total reach of 116960 people from Romania and 95 purchases. The total cost of this marketing campaign was 756.83 \$ (3100 RON), which means a cost per result of 7.97 \$ (33 RON). Considering that the average price of a school backpack is $182 \mathrm{RON}$, and one conversion was about $33 \mathrm{RON}$, that means that the advertising cost was $18 \%$ from the final price of the products.

There were three main categories of indicators: Performance, Demographic and Placement.

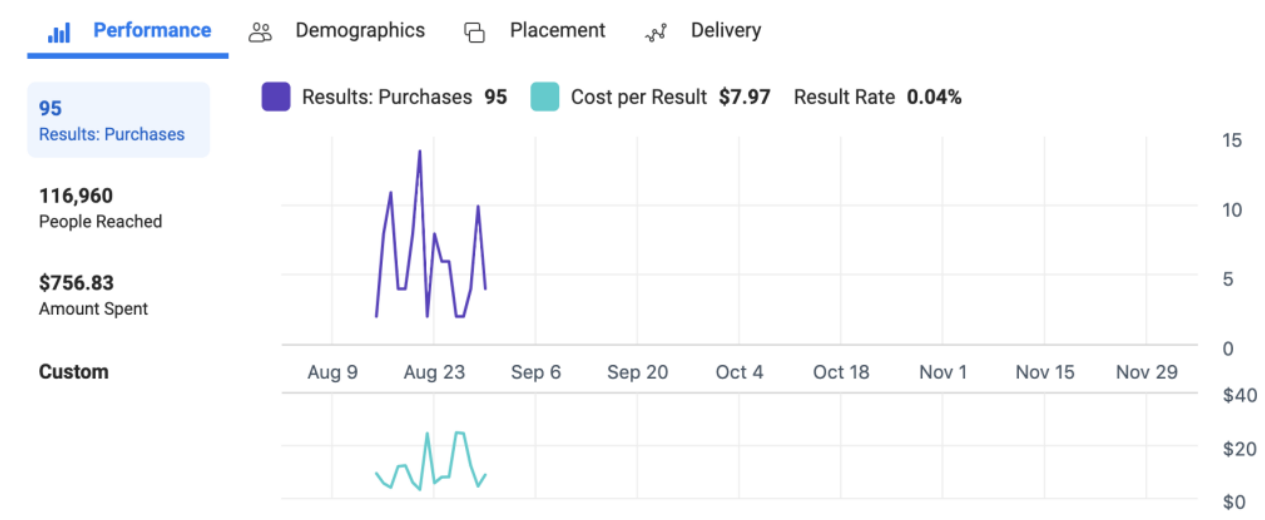

Figure 2. Indicators of the online marketing campaign 
Performance shows if the Ad was effective or not. There are more performance indicators, such as people reached, cost per result, frequency, impressions and conversions. The analysis of these indicators helps companies to improve future marketing campaigns and create better Ads. During the sixteen days of online marketing campaign we had 95 purchases, with an average cost of $7.97 \$+$ VAT. There are different costs per results every day. First day there was a higher cost, $9.81 \$$, but after that the cost decreased to $4.45 \$$. The highest cost was $24.98 \$$, on the 22nd August.

The average cost per result was very good, considering that we expect to be around $50 \mathrm{RON}+\mathrm{VAT}$.

- Reach represents the number of people who saw the Ad at least once. According to Facebook, Reach is different from Impressions, which may include multiple views of the ads by the same people.

- Impressions represent the number of times the Ad is shown on the screen for the selected target audience. That means that our Ad was shown 248370 times to the target audience (mobile and desktop). If an Ad was on the screen for someone two times, that means that there were two impressions.

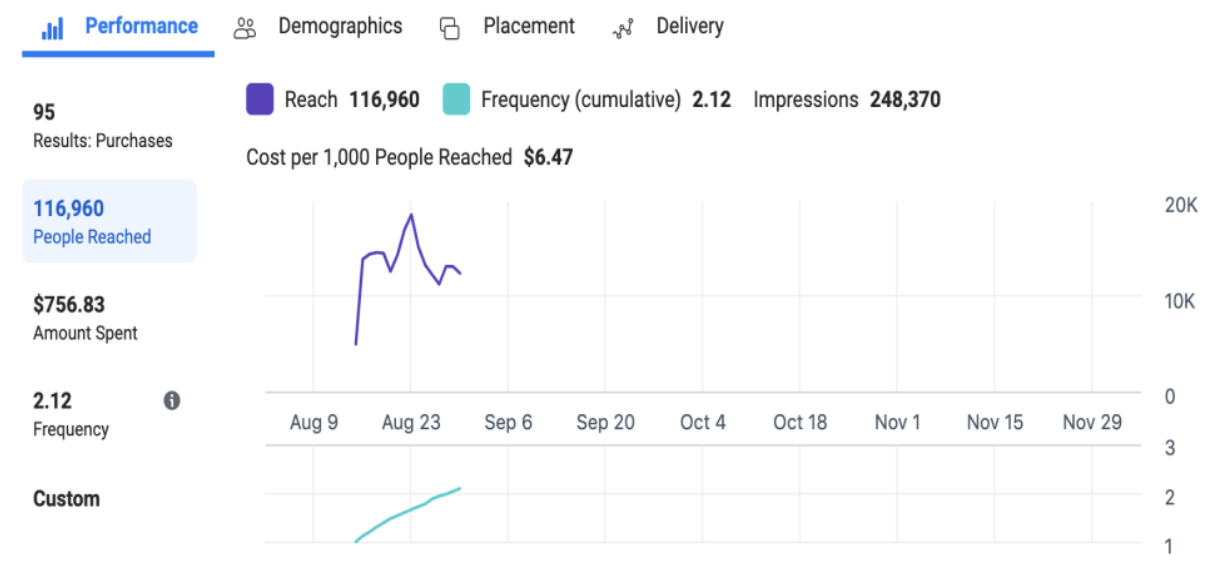

Figure 3. Performance indicators

- Frequency is the average number of times every person saw the Facebook ad. In our case the Frequency is 2.12 .

Additionally, there are more performance indicators, such as:

- Page views by source;

- People taking action;

- Actions;

- Post engagement rate;

- Likes;

- Shares;

- Comment and feedback. 
The performance indicators vary in function of the moment of day, audience characteristics or location.

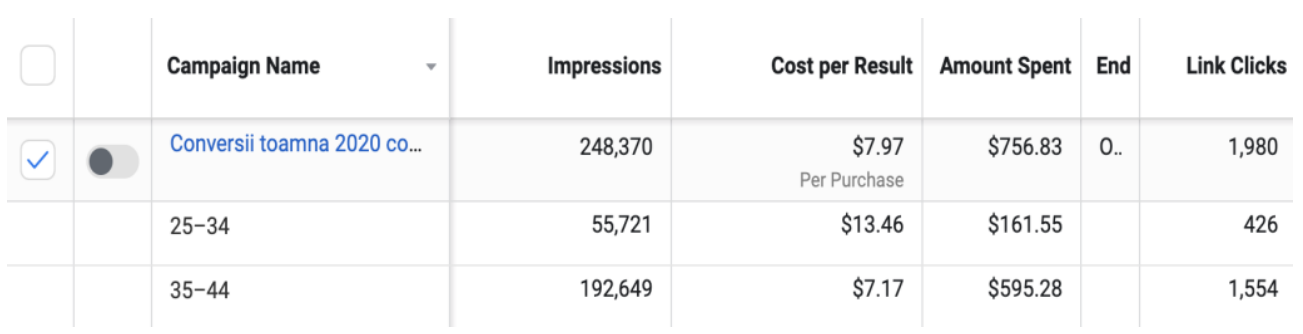

Figure 4. Performance in function of age

We observe that the best audience for these products represent people between 35 - 44 years old. The highest reach was in Bucharest with 21792 reached people, followed by Constanta with 6688 people reached and Timis with 5280 people reached. The lowest reach we got in Covasna, Mehedinti, Teleorman and Giurgiu and Ilfov counties, with a reach below 1000.

Regarding the conversions in function of time of day we observe that there are five important intervals: between 00:00 - 01:00 AM, 04:00 - 05:00 AM, 07:00 08:00 AM, 09:00 - 10:00 AM, 11:00 - 12:00, represented 56\% from the total number of conversions.

Demographic data - there is information about the audience such as age, gender, region or city.

\begin{tabular}{|c|c|c|c|c|c|}
\hline Ad Set Name & Results & Reach & Impressions & $\begin{array}{r}\text { Cost per } \\
\text { Result }\end{array}$ & Amount Spent \\
\hline Conversii toamna 2020 copii & $\begin{array}{r}95 \\
\text { Purchases }\end{array}$ & 116,960 & 248,370 & $\begin{array}{r}\$ 7.97 \\
\text { Per Purchase }\end{array}$ & $\$ 756.83$ \\
\hline $25-34$ & 12 & 27,328 & 55,721 & $\$ 13.46$ & $\$ 161.55$ \\
\hline $35-44$ & 83 & 89,632 & 192,649 & $\$ 7.17$ & $\$ 595.28$ \\
\hline \multirow[t]{2}{*}{$\triangle$ Results from 1 ad set $\theta$} & 95 & 116,960 & 248,370 & $\$ 7.97$ & $\$ 756.83$ \\
\hline & Purchases & People & Total & Per Purchase & Total Spent \\
\hline
\end{tabular}

Figure 5. Conversion by age

We targeted women between 25 - 44 years old from all Romania's regions. The marketing campaign was the most effective for women between 35 - 44 years old, with 83 conversions, 116960 reach and 248370 impressions. The cost of purchase was $7.97 \$$, similar to the cost per result for the other age interval 25 - 34 years old. Considering the results, we can confirm that women between 35 - 44 years old, from Bucharest, Constanta, Timisoara are the best audience for this fashion brand. 


\begin{tabular}{|c|c|c|c|c|c|c|c|}
\hline Ad Set Name & - & Impression: & $\begin{array}{r}\text { 2-Second } \\
\text { Continuous } \\
\text { Video Plays }\end{array}$ & $\begin{array}{r}\text { Cost per 2- } \\
\text { Second } \\
\text { Continuous }\end{array}$ & $\begin{array}{r}\text { 3-Second } \\
\text { Video Plays }\end{array}$ & $\begin{array}{r}\text { Cost per 3- } \\
\text { Second } \\
\text { Video }\end{array}$ & $\begin{array}{l}\text { 10-Second } \\
\text { Video Views }\end{array}$ \\
\hline Conversii toamna 2020 copii & Of & 248,370 & - & - & 35,897 & $\$ 0.02$ & 13,698 \\
\hline $25-34$ & & 55,721 & - & - & 7,788 & $\$ 0.02$ & 2,962 \\
\hline $35-44$ & & 192,649 & - & - & 28,109 & $\$ 0.02$ & 10,736 \\
\hline$>$ Results from 1 ad set $\theta$ & & $\begin{array}{r}\mathbf{2 4 8 , 3 7 0} \\
\text { Total }\end{array}$ & $\overline{\text { Total }}$ & Per Action & $\begin{array}{r}35,897 \\
\text { Total }\end{array}$ & $\begin{array}{r}\mathbf{\$ 0 . 0 2} \\
\text { Per Action }\end{array}$ & $\begin{array}{r}13,698 \\
\text { Total }\end{array}$ \\
\hline
\end{tabular}

Figure 6. Video visualization in function of age

The video Ad was seen by 13698 people (10 seconds of the video Ad, which means the entire video). There were 2962 views for the category "women with age between 25 - 34 years old" and 10736 views for the category "women with age between 35 - 44 years old". The majority of women who viewed this video Ad were from the biggest city of Romania.

Placement data - shows what is the ad's performance across different placements. Depending on where the ad is enabled to appear, there are details about the device type or impressions device.

\begin{tabular}{|c|c|c|c|c|c|}
\hline Ad Set Name & Deli & Reach & Frequency & $\begin{array}{r}\text { Cost per } 1,000 \\
\text { People Reached }\end{array}$ & Impressions \\
\hline Conversii toamna 2020 copii & - & 116,960 & 2.12 & $\$ 6.47$ & 248,370 \\
\hline Device: Other & & - & - & - & 3 \\
\hline Device: iPod & & - & - & - & 1 \\
\hline Device: iPhone & & 26,368 & 2.31 & $\$ 8.43$ & 61,007 \\
\hline Device: IPad & & 384 & 1.00 & $\$ 3.70$ & 384 \\
\hline Device: Desktop & & 1,184 & 1.43 & $\$ 6.96$ & 1,697 \\
\hline Device: Android Tablet & & 416 & 1.40 & $\$ 3.03$ & 583 \\
\hline Device: Android Smartphone & & 90,464 & 2.04 & $\$ 5.79$ & 184,695 \\
\hline$>\quad$ Results from 1 ad set $\mathbf{\theta}$ & & 116,960 & 2.12 & $\$ 6.47$ & 248,370 \\
\hline & & People & Per Person & Per 1,000 People Re... & Total \\
\hline
\end{tabular}

Figure 7. Impression device

The audience used smartphones to see the video Ad. 90464 people used Android Smartphones to see the video Ad, which means $78 \%$ from the total number of people who viewed the AD.

$70 \quad$ Review of International Comparative Management

Volume 22, Issue 1, March 2021 
We observe a higher frequency for Android Smartphones, which means that Facebook considers this channel most efficient in this case, showing it more often on this device type.

109920 people reached this video Ad from Facebook, which means that $94 \%$ of reach is from this platform. The Instagram reach was 11360 people and Messenger reach was 51 people.

\section{Facebook Ads Conversion}

Conversions means the number of times a specific action was taken during a given period of time. This is one of the most valuable indicators of an online marketing campaign. The number of conversions that are attributed to impressions, reach or visits may vary depending on the attributions selected. The conversions could vary in function of the day of campaign, age, gender, platform or device type or depending on the moment of day. There are many factors which influence conversions, so that's why it is indicated to analyze each campaign and make improvements.

The cost per conversion means the average cost per each conversion. In our case the cost per conversion is $7.97 \$(33 \mathrm{RON}+\mathrm{VAT})$. For the age interval $25-35$, there are 12 conversions and the cost per result is $13.46 \$$. For the age interval 35 44 , there are 83 conversions and the cost per result is $7.17 \$$. This shows again that the age interval 35 - 44 is much more attractive, generating more conversions at a lower cost. conversions:

Depending on the online marketing campaign goals, there are many types of

- Making a purchase, in this case it is our main objective;

- Sending a message;

- Calling a business;

- Engaging with the Facebook page or website;

- Registering on the website;

- Downloading a file;

- Upgrading the service version;

- Engaging with the website.

There are many conversion actions people can take on a website, this should be a measurable action that progresses a potential customer to become a paying customer. Additionally, to the conversion rate, there are more online marketing campaign benefits such as: post engagements, likes, shares, which helps the business to increase brand awareness and increase brand's loyalty.

According to the Business Manager outputs, the conversion rate is $4 \%$.

According to Facebook Business Help Center, the conversion rate could be calculated using this formula:

\section{Conversion rate $=($ Number of conversions $) /($ Total visits $) \times 100$}


In time, the conversion rate is higher due to people who see the video Ads and buy a product later. Also using a video Ad could increase the brand loyalty, existing clients could buy even more in the future. A Facebook Page is more likely to be appreciated by a person if his friends like or share any information about this brand. So that's why we consider that the conversion rate formula should be improved with people who see the online marketing campaign and buy in the future. There are more indicators to be considered, such as post engagement and post reactions. These are generated by people who are interested in the promoted product/service, they like it, they ask for additional information or they want to share it with their friends.

Post engagement includes all actions that people take when seeing the Ad. It could include actions like reacting to, commenting on or sharing the Ad, claiming an offer, clicking a link. The post engagement shows that the Ad is relevant for the selected target audience because when people see an Ad that is relevant for them, they are more likely to interact with it. Post reactions include all reactions on the ad: like, love, sadness, anger, laugh and other reactions. They indicate that the Ad is relevant for the selected target audience and engage people more with the brand.

ROAS, return on Ad spend, is one of the most important metrics for a social marketing campaign. This is important because marketing is an investment for the company. Calculating ROAS we can validate which marketing channels are the most efficient and which are not. In this case the website purchase ROAS is 2.54 . That means that for $1 \$$ invested into the Facebook Ad campaign, the company we'll get $2.54 \$$

\section{Conclusions}

Development of social media networks has led to big challenges and changes in marketing strategies. Companies are now integrating social media into their marketing plan, having different objectives, such as to increase revenues, to increase brand awareness, to communicate with clients or to create communities. The customization strategy, allowed by social media, addresses the increasing customer need for each person, rather than mass products, and can contribute to higher retention and efficient branding (Constantinides, 2014).

We created a Facebook marketing campaign to increase the sales of a local fashion brand. This marketing campaign was active between 15 August to 30 August 2020 and we used a 7 seconds video. These products are dedicated to teenagers and the customers are their parents, especially their mothers. The main objective of this marketing campaign was "Conversions". In this case one conversion means one purchase. During the sixteen days of campaign there were 95 purchases, generating a website purchase conversion of $1923.71 \$$. The average cost of one conversion was 7.97 + VAT (33 RON + VAT), which is less than the amount we expect to be, 50 RON + VAT.

We observed that the best audience for this marketing campaign were women between 35 - 44 years old. The highest reach was in Bucharest with 21792 people reached, followed by Constanta with 6688 people reached and Timis with 
5280 people reached. These locations are followed by big Romania cities, such as Ploiesti, Iasi and Cluj-Napoca. The selected audience used smartphones to see the Facebook Ad and usually they buy products during the night or in the morning. For a better performance, the next marketing campaigns should target women between 35 - 44 years old, from big cities, which use especially mobile devices to check Facebook and buy products.

Creating a Facebook Business Manager, companies could create complex marketing campaigns, being able to improve it all the time. Companies should evaluate each marketing campaign performance and its effect on business. We consider the best way to check the performance of a Facebook Ad is to consider indicators such as ROI (Return-on-investment) or ROAS (Return on Ad spend), which explain better the benefits and results of a Facebook Ad.

\section{Acknowledgment}

PN-III-P1-1.2-PCCDI-2017-0800 Empirical modeling and experimental development of tools associated with technologies in the field of online social networks - 86PCCDI/2018

\section{References}

1. Alves, A., Fernandes, I. C. \& Raposo M., 2016, Social Media Marketing: A literature Review and Implications: implication of social media marketing, Psychology and Marketing 33(12):1029-1038 DOI: 10.1002/mar.20936, pp. 1029 - 1038

2. Appel, G., Grewel, R. Hadi, R., Stephen A. T., 2019, The future of social media in marketing, Journal of the Academy of Marketing Science volume 48, 79 - 95(2020)

3. Bala, M., Verma D., 2018, A critical review of digital marketing, International Journal of Management, IT \& Engineering, 8(10), pp. 321-339.

4. Barker, M,. Barker, I. D., Bormann, F. N., \& Zahay D., 2014, Social media marketing: A strategic approach, Cengage Learning; 2nd edition, pp. 2 Constantinides, E., 2014, Foundations of social media marketing, https://doi.org/10.1016/j.sbspro.2014.07.016, Volume 148, pp. 40-57

5. Iblasi, N. W., Bader M. K. D., Al-Qreini S. A., 2016, The impact of social media as a marketing tool on purchasing decision (Case study on Samsung for Eletrical Home Appliances), International Journal of Managerial Studies and Research (IJMSR) Volume 4, Issue 1, PP 14-28 ISSN 2349-0330

6. Krishnan, K, Rogers P. S. (2014), Social Data Analytics: Collaboration for the Enterprise,edition, Edition, Morgan Kaufmann; 1 edition, pg. 2

7. Miller, R., 2020, Social Media Marketing Mastery 2020:3 BOOKS IN 1-How to Build a Brand and Become an Expert Influencer Using Facebook, Twitter, Youtube \& Instagram-Top Digital Networking \& Personal Branding Strategies, ISBN-13 : 9798638187521, Independently published, pp. 7

8. Sharma S., Verma, H. V., 2018, Social media marketing: Evolution and change, Social Media Marketing, pp 19-36

9. Star, D., Marsico, M., Hernandez, E., 2020, Digital marketing 2020: Grow your business with digital marketing, Kindle edition Facebook Business Help Center, 2020, Reach, Available at: https://www.facebook.com/business/help/710746785663278, [Accessed 15 November 2020]. 